\title{
In memoriam: Tapan Biswas (1942-2010)
}

\author{
GIANLUIGI PELLONI \\ University of Bologna, Rimini Centre for Economic \\ Analysis (RCEA) and Wilfrid Laurier University
}

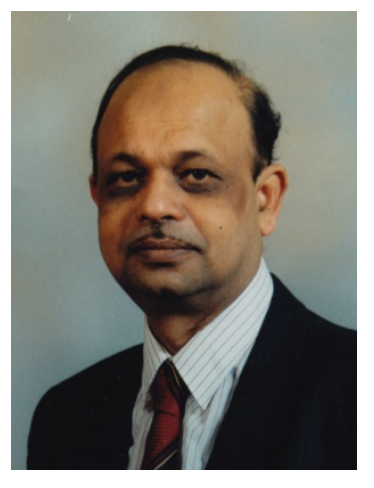

Tapan was born in Kolkata (Calcutta), India, on April 16th 1942. He spent his early formative years in his native city where he attended the Scottish Church Collegiate School. Although Tapan loved literature and music, his teachers encouraged him to use his mathematical talents for a career of greater security. His interest in Bengali classical music, literature and films continued throughout his life. Though Tapan, in later years, would travel the world and spend most of his life abroad, his intellectual and spiritual character was closely intertwined with the culture of Bengal and India. Following the advice of his mentors, he entered Presidency College in Kolkata to read Economics and Political Science. Tapan thrived in the educational excellence of Presidency College, an experience which widely expanded his intellectual horizon. Throughout his life he always remembered with gratitude, affection and respect the high standards of his teachers and classmates. Tapan was born in a modest background and, during his college years, had to work tutoring younger students in order to pay his way through his studies. After being awarded a B.A. Honours in Economics and Political Science in 1963 from Presidency College, he progressed to the University of Calcutta, where he obtained an M.A. Economics in 1966.

After a two years stint as lecturer at Maulana Azad College in Kolkata, Tapan received a scholarship which allowed him to embark on his research degree studies in the Department of Economics University of Rochester, USA. En route to America, leaving India for the first time, he took advantage of an open ticket and visited six countries in as many days, across Europe and Africa, with barely a handful of notes in his wallet. If luck is when talent and hard work meet opportunity, then he was lucky again. Tapan, who had a strong interest in Economic Theory, International Trade and Development Economics, was enthralled by the excellence in research and teaching at Rochester Economics Department and especially by the brilliance of Lionel McKenzie and Ronald Jones. In 1971 he worked as Assistant Lecturer in 
the Rochester Department and in 1972 he received his Ph. D. with a thesis on " Non-shiftable Capital and Imported Inputs in the Theory of International Trade and Economic Growth", with Lionel McKenzie and Emmanuel Drandakis as supervisors.

After obtaining his doctorate, Tapan worked at the University of California in Santa Barbara, U.S.A. (1972-74), and the University of Manchester, U.K. (1974-76), before returning to India at Panjab University, Chandigarh where he stayed for the period 19761979, serving as Chairman and Head of the Department of Economics (1977-79). During that period he was a member of the northern wing of the Executive Committee of the Indian Council of Social Science Research (ICSSR).

In July 1973 Tapan married Sabita Sarkar. Their son Subha Brata Biswas was born in May 1978, and the strong tie of love, understanding and respect with his family became a focal point of Tapan's life, both as an individual and a scientist. Tapan moved back to the West with his family with a Hallsworth Fellowship at the University of Manchester (1979-80) and in 1980 joined the Department of Economics of University of Hull where he remained, moving to the Business School in 2000, until his retirement (as Senior Lecturer) in 2007.

During his career Tapan served as Visiting Associate Professor at Queen's University, Canada (1985-86) and also held Visiting Scholarships at the Centre for Economic Studies (CES), Munich University, Germany (January 1992), and the Centre for Operations Research and Econometrics (CORE), Louvain la Neuve, Belgium (July 1992). He remained an active conference participant, journal reviewer, book reviewer and conference organiser throughout his professional life. In recent years, Tapan was a founding member and former President of International Economics and Finance Society (IEFS - UK) and of the European Economics and Finance Society (EEFS). His involvement and encouragement were crucial for both societies were crucial at the take off stages. His support was equally important at the Rimini Centre of Economic Analysis (RCEA), where he was a Senior Research Fellow and a member of the Executive Board of the Review of Economic Analysis (REA).

After retirement Tapan continued to be engaged in research (mostly with a young and enthusiastic colleague, Jolian McHardy), and in actively contributing to workshops, conferences and editorial services. He sorely missed teaching, an activity which he loved and in which he excelled. On 3rd July 2010, Tapan unexpectedly and prematurely died of a heart attack at his home in Cottingham in East Yorkshire. At the time of his death he was still fully active and had a few articles ready for publication while other projects were under way. He died as he lived: peacefully and surrounded by the love of his family.

As a teacher Tapan had all the hallmarks of a true scholar. His instruction was always informed and lucid, not only to students but also to colleagues. Notwithstanding the formidable mathematical knowledge at his command, Tapan never overburdened his lectures with formalism but instead aimed at providing a logical structure which the students could follow, whatever the obstacles. He lectured without notes, believing that someone could teach 
a subject only when that subject "belongs to his heart". His lectures were then an affair between his thoughts, his communication ability, and the students - with no other intermediary than the blackboard. Students loved his teaching for its clarity and thoroughness, and loved the teacher for his kindness and openness. If, where he taught, there would have been a prize for the best teacher of the year, he would have probably won it several times. A lesson not to be lost in an age where the use of power point presentations, transparencies and floods of handouts have overtaken the need for natural teaching prowess. His humble and unassuming outlook, combined with his exceptional ability, made of Tapan a role model for his students as much as for his colleagues.

Tapan was a formidable and indefatigable researcher and scholar, with an open and restless mind. In his research, as in his teaching, it was the conceptual aspect of his work that mattered, and not the technical apparatus. If he needed difficult techniques to say what he needed to say, he would use them, but he did not make the display of technical prowess the focus of his work. Technique was only a means to an end. Tapan worked mostly alone, but occasionally he had co-authors. He was very cautious and selective in his choice of collaborators (not only ability counted but also the right attitude towards research), as he was in making friends. However, once he had made his choice he was immensely loyal and appreciative of them.

Tapan was first and foremost a theorist, with a wide and varied knowledge and interests. Microeconomics, general equilibrium, international trade, economics of uncertainty, game theory, and public economics were his main fields. He also maintained a strong interest in development and labour economics. He published work on the intertemporal non-optimality of investment myopic decision rules (Journal of Economic Theory, 1974); on complementarity over time in models of optimal growth, establishing that an extension of the Edgeworth-Pareto criterion could dominate other approaches (The Review of Economic Studies,1976); on Marshallian theory of demand, showing that Hick's criticism of Marshal regarding the ambiguity of the direct price effect is unfair because Marshallian demand theory assumes a concave utility function for the relative optimization problem rather than the quasiconcavity assumption of Hicks (Economica, 1977); on the theory of production, where he proved that the Jacobian matrix of all excess demand functions may satisfy the gross substitution requirements (Mathematical Social Sciences, 1985); on distributive justice, allocation by the market and the concept of a fair market economy (Mathematical Social Sciences, 1987); on monopolistic competition showing that an equilibrium under monopolistic competition can be Pareto efficient (Keio Economic Studies, 1990), on risk aversion with three main contributions: first he proposes a generalization of the Arrow-Pratt measure by introducing two alternative measures, one of which could be linked to the Khilstrom-Mirman measure and providing on the way a proof for the latter in the ndimensional case as it was originally left as a conjecture by its authors ( Journal of Economic 
Theory, 1983), second his work on stochastic dominance and comparative risk aversion in a volume of collected writings (Essays in Economic Analysis and Policy, ed. D. Banerjee, Oxford University Press, 1991) and third the advanced overview of this topic he presented in his book (Decision-Making under Uncertainty, Macmillan, 1997); on social choice where he takes into consideration the preference of a significant minority who would lose under the simple Borda rule (Public Choice, 1994); on competitive equilibrium by proving its existence and uniqueness for certain kind of mapping even if the mappings are only upper-semicontinuous, results of great relevance for the gross-substitution case in general equilibrium and the relative factor-price equalization theorem in trade theory (Journal of Mathematical Economics, 1994, jointly with Taradas Bandyopadhyay) and by presenting a n-commodity, nfactor generalization of the Stolper-Samuelson Theorem (Journal of Quantitative Economics, 2000, jointly with Taradas Bandyopadhyay). In recent years Tapan published articles on migration and labour issues in collaboration with Jolian McHardy. Their last published work together deals with input efficiency within a spatially segregated Cournot duopoly with monopoly trade unions whose utility functions depend on both wages and employment (Journal of Economic Behaviour and Organization, 2007). At the time of Tapan's death they were completing other work which would soon be published.

Although incomplete, the above account of his contributions alone is evidence enough of the remarkable prowess of Tapan as a researcher. Nevertheless, it does not and cannot do justice to Tapan as a scholar and as a scientist. Tapan was a law unto himself and his professional life was devoted to the academic ideals that he set himself. If we accept Albert Einstein's subdivision of scientists into the three categories of the "athlete scientist", the "career scientist" and the "spiritual scientist", Tapan would certainly belong to the latter. For the "athlete scientists" scientific activity is a kind of sport which allows them to display their particular talent. "Career scientists" become scientists only because some circumstance has favoured that career choice as one with a profitable return. "Spiritual scientists" form the smallest and most elusive group. Though often different from each other in intellectual outlook and appearance, they are united by an ideal to unshackle the chains of the merely personal, of transient desires and primitive feelings. This type of scientist tries to construct a picture of what the human mind sees in nature and society and "within this picture he places the center of gravity of his own soul, so that he will find in it that rest and equilibrium which he cannot find within the narrow circle of his restless personal reactions to everyday life". Tapan's preoccupation throughout his life with foundational issues can be understood only in this perspective. It was the process of making science and not records or career that mattered to Tapan. He was not concerned about what other people or academics in authority thought of him, he lived only for his own ideal to be true to his field of science and to himself as a scientist. If this kind of integrity led him to discard some of his work and to a relatively lower productivity, with possible damage to his career in a world praising quantity over quality, so 
In memoriam: Tapan Biswas (1942-2010)

be it. Tapan the scientist had to live in full harmony with Tapan the man. His formidable scholarship could not be separated from his deep human nature. It could not be separated from his spirituality and religiosity, his kindness, his profound ties to his family, his love and loyalty towards friends, his humility and simplicity, his lack of malice and bitterness (despite suffering cruel injustices himself). Tapan's scholarship can be understood and fully appreciated only within the "wholeness" of his nature. A nature which was complex but not complicated. A nature in which each component was strictly integrated with all the others and which strode through life with delicate, sensitive and wise harmony. A noble nature which was at peace with itself. All those who had the fortune to spend time in Tapan's company could sense this inner harmony and repose, and could draw from it a profound and enriching experience.

Tapan is survived by his wife Sabita and his son Subha Brata, a qualified medical General Practitioner (GP).

Dr. Tapan K. Biswas, University Economist, born 16 April 1942 (Kolkata, India), died 3 July 2010 (Cottingham, East Yorkshire, UK)

\section{References}

Bandyopadhyay, Taradas \& Tapan Biswas (2012), Least Concave Ordinal Utility Function and Marshallian Cardinal Utility, Review of Economic Analysis 4(1), 9-16.

Biswas, Tapan and Jolian McHardy (2007), Asking Price and Price Discounts: The Strategy of Selling an Asset under Price Uncertainty, Review of Economic Analysis 4(1), 17-37. Originally published in Theory and Decision 62(3), 281-301.

Biswas, Tapan and Jolian McHardy (2007), On the Incentives to Increase Input Efficiency under Monopoly Trade Unions, Review of Economic Analysis 4(1), 39-51. Originally published in Journal of Economic Behavior \& Organization, 62(4), 657-669.

Bandyopadhyay, Taradas and Tapan Biswas (2000), The Relation between Prices of Factors and Goods in General Equilibrium, Review of Economic Analysis 4(1), 53-65. Originally published in Journal of Quantitative Economics, pages 53-64, July.

Biswas, Tapan (1996), Weak* Axiom of Independence and the Non-expected Utility Theory, Review of Economic Analysis 4(1), 67-75. Originally published in Economic Theory Trade and Quantitative Economics: Essays in honour of Professor P.N. Roy (eds. A.Banerjee and B. Chatterjee), Calcutta University Press

Biswas, Tapan (1994) Efficiency and Consistency in Group Decisions, Review of Economic Analysis 4(1), 77-88. Originally published in Public Choice, 80(1-2), 23-34. 
Bandyopadhyay, Taradas and Tapan Biswas (1994), Global Univalence when Mappings are Not Necessarily Continuous, Review of Economic Analysis 4(1), 89-104. Originally published in Journal of Mathematical Economics, 23(5), 435-450.

Biswas, Tapan, (1991), Stochastic Dominance and Comparative Risk Aversion, Review of Economic Analysis 4(1), 105-122. Originally published in Essays in Economic Analysis and Policy (ed. D. Banerjee), Oxford University Press, 113-30.

Biswas, Tapan (1990), Monopolistic Competition in a Large Economy, Review of Economic Analysis 4(1), 123-129. Originally published in Keio Economic Studies, 26, 65-71.

Biswas, Tapan (1987) Distributive Justice and Allocation by the Market: On the Characterisation of a Fair Market Economy, Review of Economic Analysis 4(1), 131-143. Originally published in Mathematical Social Sciences, 14(3), 225-237.

Biswas, Tapan (1985), Factor-Supply Responses and the Gross-Substitute System, Review of Economic Analysis 4(1), 145-149. Originally published in Mathematical Social Sciences , 9, 183-87.

Biswas, Tapan (1983), A Note on the Generalised Measures of Risk Aversion, Review of Economic Analysis 4(1), 151-156. Originally published in Journal of Economic Theory, 29(2), 347-352.

Biswas, Tapan (1974), Non-optimality of the Myopic Decision Rule: The Case of a Twosector Open Economy, Review of Economic Analysis 4(1), 157-163. Originally published in Journal of Economic Theory, 7(1), 115-121.

Biswas, Tapan (1977) The Marshallian Consumer, Review of Economic Analysis 4(1), 165174. Originally published in Economica, 44(173), 47-56.

Biswas, Tapan (1976), A Note on Complementarity over Time, Review of Economic Analysis 4(1), 175-177. Originally published in Review of Economic Studies, 43(1), 179-81. 